\title{
Student Nurses's Stigmatising Attitudes towards Persons with a Mental Disorder in a selected School of Nursing and Midwifery in Rwanda
}

\author{
Vedaste Baziga*
}

\begin{abstract}
School of Nursing and Midwifery, University of Rwanda

Mental disorders (MD) contribute significantly to global burden of disease and this is the fourth leading cause of global disability. To find out the solutions of this issue, the World Health Organization recommended integration of mental health care into general health care facilities and nurses have an important role in implementation of WHO recommendation regarding the integration. A quantitative, non-experimental, descriptive cross sectional study was conducted among student nurses in a selected School of Nursing \& Midwifery in Rwanda. A self-report questionnaire that included one section for demographic variables and two sections such as level of contact and the Community Attitudes towards Mental IIIness - Swedish version has been used. The self-report questionnaire was distributed to available students $(\mathrm{N}=158)$. These student nurses were not sampled and were all included in the audit. There were two reasons for this. Firstly, the hospital rotation of students during their clinical placement and full integration of mental services within the hospital meant that all student nurses allocated at the hospital had an equal chance of caring for MHCUs. Secondly, the researcher aimed to obtain sufficient numbers for statistical power in the data analysis, which necessitated at least 100 participants (Polit \& Beck, 2012).

The next step was data analysis where SPSS version 20 was used. This study revealed that participants held negative stereotypes towards persons with MD. However, the findings revealed contradictions that are suggested to be the effect of social desirability bias. Association test revealed less negatives stereotypes towards MD amongst year 4 students and students with scientific background than year 1, 2 \& 3 students and students with social sciences background. Also, correlation test revealed that increases in Level of contact with MD correlates with decrease of negative stereotypes towards persons with MD.
\end{abstract}

Key words: Student Nurse, mental disorder, stigmatizing attitude, familiarity

\section{Introduction}

Mental disorder is defined as a clinically significant behavioural or psychological syndrome, or pattern, that occurs in an individual and is associated with distress or disability or with an increased risk of suffering death, pain, disability, or an important loss of freedom. Mental health \& substance abuse is leading cause of disability (Whiteford et al., 2013) and mental disorders represent $13 \%$ of the global burden of disease and have a global prevalence ranging between $4 \%$ and $26 \%$ (World Health Organisation (WHO) 2011). However, the estimate increases to $23 \%$ in high income countries (WHO,2011; Burns, 2011; Callaghan, Playle, \& Cooper, 2009).

The World Health Organisation recommended the integration of mental health care into general health care facilities to reduce mental health related problems considered as global and local burden (WHO, 2013). This integration is so important in Rwandan citizens considering the events of the 1994 genocide within Rwanda that had a significant impact on the mental health of the population, thus psychological trauma that making a burden on Rwandan mental health services (Rwandan Ministry of Health, 2011). To face genocide related mental health problems, the Rwandan Ministry of Health began integration of mental health into district hospitals settings. Such integration would rely heavily on nurses for its implementation (Ssebunnya et al., 2010; Lund, Kleintjes, Kakuma, Flisher,\&the MHaPP Research Programme Consortium, 2010). Also, students nurses who are suggested to be future registered nurses, are allowed and involved in the provision of care to persons mentally ill during their clinical placement at different level of health care system (from community to referral settings) in which the integration of mental health services are recommended to be implemented (University of Rwanda/ College of Medicine and Health Sciences, 2016).

That implementation of this integration is largely done by nurses and/ or students nurses, is of special consideration in the context of Rwandan mental health care. This is confirmed by the Rwandan Ministry of Health (2005) acknowledging the nurse as the team member who has the most contact with the mental health care users (MHCUs), both in inpatient and outpatient settings. In this regards, the WHO (2011) reporting that nurses (psychiatric and non-psychiatric) globally represent the most prevalent professionals working in mental health sector, estimated at 5.8 per 100000 population. Nevertheless, Rwanda is facing a challenge related to the shortage of mental health practitioners, specifically nurses.

The mental health nurse to population ratio is reported to be 0.8 mental health nurses per 100000 of the population (WHO, 2005), while the general nurse-population ratio in Rwanda is estimated at 58.8 general nurses per 100000 population (Rwandan Ministry of Health, 2009). Despite current literature suggesting that the integration of mental health care services into general healthcare settings, specifically PHC, will reduce stigmatizing attitudes towards mental disorders, there have been consistent reports that one of the barriers of integrating mental health care into mainstream healthcare has been health care professionals' negative attitudes with stigma components towards persons diagnosed with mental disorders (Kapungwe, Cooper, Mayeya, Mwanza, Mwape,\& Sikwese, 2010; Ssebunnya et al., 2010; Mwape, Mweemba, \& Kasonde, 2012).Current literature suggests that health care providers, including nurses or students nurses during their clinical placement, are not immune to these social prejudices and that they have the same negative attitudes as the general public regarding mental disorders (Arvaniti, Samakouri, Kalamara, Bochtsou, Bikos, \& Livaditis, 2009). In Rwanda there is no studies conducted about mental health related stigma amongst Rwandan population. However, a study conducted in a selected District Hospital revealed stigmatizing attitudes towards MD amongst nurses. who are suggested to be involved in the process of integration of mental health services in general health care facilities (Vedaste \& Smith, 2016). 
Anti-stigma initaives suggested to positively impact on these negative steretypes generally include education, information sharing about mental disorders, and, familiarity through increased contact, research indicating that both are positive mediators of negative mental disorder stereotypes (Arvaniti et al., 2009; James, Omoaregba, \& Okogbenin, 2012; Corrigan, Powell, Fokuo \& Kosyluk, 2014; Corrigan, Mittal, Reaves, Haynes, Han, Marris, 2014). Despite Rwandan integration of mental health services beginning in 2005 , there is no local research regarding mental disorder stigmatising attitudes among students nurses tasked with implementing integrated care (Rwandan Ministry of Health, 2009). When the ministry is rolling out the inclusion of mental health services at the different levels within the main health care services, it is suggested as pertinent to establish if negative attitudes amongst nurses could pose a potential barrier.

The purpose of this study is to describe stigmatising attitudes towards a person with MD amongst student nurses as future nurses who will be allocated in different level of health care in Rwanda which integrating mental health care services to inform anti stigma initiatives to reduce stigma in health care professionals. This study was addressing research questions as follows: (1) what stereotypical attitudes are most or least evident amongst student nurses? (2)To what extent students' nurses' attitudes reflect an openness and willingness regarding integration of mental health care into general health care setting? (3)To what extent do students nurses attitude reflect fear and avoidance related to person with mental disorders? (4)What demographic variables have a mediating effect on negative stereotypical attitudes held by students' nurses towards people with a mental disorder? (5)Does familiarity mediate negative stereotypical attitudes held by student nurses towards persons with a mental disorder? (6)What demographic variables are more or less evident as potential mediators of stigmatizing attitudes?

This paper is composed of four sections such as introduction, methods, results and discussion.

\section{Methods}

This study adopted a quantitative, non-experimental, descriptive cross sectional survey design that made use of a self-report questionnaire to facilitate an audit of the attitudes of student nurses with regard to mental disorder.

The self-report questionnaire was divided into three sections and contained two data collection instruments. The first section established demographic data (Age, gender, Background in Secondary school, Level of Academic year). The second section contained the level of contact scale (LOC) designed by Corrigan and colleagues (Corrigan et al 2001) aimed at measuring the extent of participants familiarity with persons with a mental disorder. The third section contained the Swedish version of the Community Attitudes towards Mental IIIness (CAMI) instrument (Hogberg and colleagues (2008). The original CAMI and LOC have been used extensively since and has shown high validity and reliability (Morris et al., 2011; Ukpong \& Abasiubong, 2010; Barke et al., 2011).The self- report questionnaire was not translated into French as long as English is the teaching medium in high learning institutions in Rwanda.
The reliability of LOC has been reported by Holmes and colleagues (1999) to have inter-rater reliability of 0.83 . Informed implied consent was used. The rationale for the use of informed implied consent was to reduce participants' perceived risk to anonymity and confidentiality, and to attempt to reduce social desirability bias influencing participants' responses. This issue of discrimination is specifically sensitive in Rwanda, where the genocide resulting from discrimination from one group to another is a source of national shame.Rwandan population is sensitive to their behaviour, both verbal and nonverbal, being deemed discriminatory.

\section{Research setting and participants}

The research setting was a School of Nursing \& Midwifery in Rwanda. The School of Nursing \& Midwifery is amongst different Schools within the College of Medicine and Health Sciences within the University of Rwanda.

School of Nursing \& Midwifery is composed of three departments (General Nursing, Midwifery \& Mental Health Nursing). School of nursing \& midwifery is located in four campuses such as Nyamishaba, Nyarugenge, Byumba, Kibumgo \& Nyagatare. The total number of students in the School of Nursing \& Midwifery is 906. Only General nursing department is running the Bachelor's program while Mental Health Nursing \& Midwifery are running Advanced Diploma Program.

Exit profile of students in General Nursing is as follows: Health care provider in different level of health care setting (from community level to referral level), educator, researcher and leader. The Bachelor's program is covered during four years (UR, 2013). This research was conducted only in the department of general nursing located in both Nyamishaba and Nyarugenge Campuses. The number of students in general nursing department make a total of 183 .

During their training students are being taught different modules that equip them knowledge, skills \& attitudes that make them to deal with different categories of patients during clinical placement and after graduation in professional life. These modules include also behavioural sciences and mental health nursing informing them about mental disorders in general and person with mental disorder particularly (MHCUs). Only 158 student nurses were available to participate in this study.

\section{Data collection}

Data collection followed ethical approval. The ethical approval was granted by educational institution: University of Rwanda, the CMHS INSTITUTIONAL REVIEW BOARD on behalf of the National Ethical Committee (NEC) (CMHS/IRB/261/2015). In addition University of Rwanda and specifically the management of School of Nursing \& Midwifery, permission was obtained. A meeting was held with nursing management (Department of General Nursing) and a data collection schedule was agreed upon considering the teaching time table in School of Nursing and Midwifery particularly General Nursing Department from Year 1 students to Year 4 students. 
The researcher collected data from all participants from year one to year 4 . Information sheets were distributed to all academic years by the researcher 3 days prior to data collection, and time to ask questions was given immediately prior to participation, no questions were verbalised. In addition, immediately prior to participation the researcher made a point of explaining to each potential participant group that participation was voluntary, that there was no specific answer being sought by the researcher, and that anonymity was assured, specifically that consent was implied on the posting of the completed self-report questionnaire by the participant in the sealed box provided.

\section{Data analysis}

Using a codebook data was entered into the statistical computer package SPSS, Version 20. The single highest score from the LOC was recorded. Reverse scoring was applied to items $4,5,6,10,11,12,13,17$ and 20 for the CAMI -S. Descriptive statistics computed included; measures of central tendency and distribution (Scores were tabulated for all scales and sub-scales. The decision to use nonparametric tests for further analysis was based on abnormality of the distribution of the data.

Associations were computed using the Mann whitney $\mathrm{U}$ test to compute associations of subscale scores and total score with demographic variables (gender)and the Kryskal Wallis $\mathrm{H}$ Test (associations of subscale scores and total score with demographic variables (Academic year of students). The Spearman's rho correlation coefficient test was used to compute correlations between scores achieved on the LOC, level of familiarity and scores achieved in the CAMI-S (Pallant, 2013).

\section{Ethical Considerations}

In the current study, implied consent was used as it is useful in situations where self-report questionnaires are used to collect data and the researcher wants to assure participants of anonymity and attempt to reduce responses that may represent social desirability bias in an attempt to reduce social desirability bias by increasing participant's sense of anonymity (Polit \& Beck, 2012). In addition, regarding potential risks and risk minimization, the student nurses are not considered vulnerable in the same way as MHCUs. The study was argued to be low risk research (Polit \& Beck, 2012).

\section{Results}

\section{Description of participants}

The total number of participants was $(n=158)$ and the majority included male participants $(n=92 ; 58.1 \%)$ and minority of female participants $(n=65,41.1 \%)$. Distribution of participants according to the level of academic year, was as follows; Year $1(n=45 ; 28.5 \%)$, Year $2(n=25 ; 15.8 \%)$, Year $3(n=40 ; 25.3 \%)$ and Year $4(48 ; 30.4 \%)$. Regarding the background of students in secondary school, the majority was students who did scientific option ( $n=140$; $88.6 \%$ ) while students who did Social sciences options was composed the minority of participants $(n=18 ; 11.4 \%)$. This is not surprising as longer as scientific option is one of requirements to be admitted in the program of Bachelor's of Science in Nursing. Students with background of social sciences included especially enrolled nurses who were trained in former nursing schools that were supposed to graduate A2 nurses. The response rate achieved is $86.3 \%$

\section{Level of contact}

Table 1. Level of familiarity

\begin{tabular}{|l|l|l|}
\hline Score & Level of contact & $\mathbf{N}(\%)$ \\
\hline 1 & Never observed a person with mental disorder & $0(0.0 \%)$ \\
\hline 2 & $\begin{array}{l}\text { Observed in passing a person with mental disorder in } \\
\text { passing }\end{array}$ & $1(0.6 \%)$ \\
\hline 3 & Watched a movie or television show & $3(1.9 \%)$ \\
\hline 4 & Watched a documentary or television & $7(4.4 \%)$ \\
\hline 5 & $\begin{array}{l}\text { Observed a person with severe mental disorder on } \\
\text { frequent basis }\end{array}$ & $1(0.6 \%)$ \\
\hline 6 & $\begin{array}{l}\text { Worked with a person who had mental disorder at my } \\
\text { place of employment }\end{array}$ & $6(3.8 \%)$ \\
\hline 7 & $\begin{array}{l}\text { Clinical placement includes providing services to } \\
\text { person with severe mental disorder }\end{array}$ & $29(18.4 \%)$ \\
\hline 8 & $\begin{array}{l}\text { Clinical placement involves providing services or } \\
\text { treatment to person with severe mental disorder }\end{array}$ & $25(15.8 \%)$ \\
\hline 9 & A friend of my family has a mental disorder & $25(15.5 \%)$ \\
\hline 10 & I have a relative who has a severe mental disorder & $28(17.7 \%)$ \\
\hline 11 & I live with a person who has mental disorder & $22(13.9 \%)$ \\
\hline 12 & I have severe mental disorder & $11(7.0 \%)$ \\
\hline
\end{tabular}

As displayed in table 1, participants' level of contact, measured by the LOC scale, ranged between a score of 2 Observed a person with mental disorder in passing $(0.6 \%$, $\mathrm{n}=1$ ) and a score of 12 , I have a severe mental disorder $(7 \%, \mathrm{n}=11)$. The most commonly occurring score was level 7 , providing services to person with severe mental disorder $(18.4 \%, n=29)$. 


\section{Results from the CAMI-S}

Table 2. Response to statements on the CAMI-S

\begin{tabular}{|c|c|c|c|c|c|}
\hline \multirow{2}{*}{$\begin{array}{l}\text { Item statements } \\
\text { Subscale 1: open minded and pro-integration }\end{array}$} & \multicolumn{5}{|c|}{ Participant responses } \\
\hline & SA & $\mathbf{A}$ & $\mathbf{N}$ & $\mathbf{D}$ & SD \\
\hline $\begin{array}{l}\text { 1. Residents should accept the location of mental health } \\
\text { facilities in their neighbourhood to serve the needs of } \\
\text { the local community }\end{array}$ & $58(36.7 \%)$ & $36(22.8 \%)$ & $19(12 \%)$ & $14(8.9 \%)$ & $31(19.6 \%)$ \\
\hline $\begin{array}{l}\text { 2. Most persons who were once patients in a mental } \\
\text { hospital can be trusted as babysitters }\end{array}$ & $\begin{array}{l}38 \\
(24.1 \%) \\
\end{array}$ & $\begin{array}{l}39 \\
(24.7 \%) \\
\end{array}$ & $28(17.7 \%)$ & $39(24.7 \%)$ & $14(8.9 \%)$ \\
\hline $\begin{array}{l}\text { 3. Locating mental health services in residential } \\
\text { neighbourhoods does not endanger local residents }\end{array}$ & $32(20.3 \%)$ & $47(29.7 \%)$ & $27(17.1 \%)$ & $45(28.5 \%)$ & $7(4.4 \%)$ \\
\hline $\begin{array}{l}\text { 4. Mental health facilities should be kept out of } \\
\text { residential neighbourhoods }\end{array}$ & $36(22.8 \%)$ & $38(24.1 \%)$ & $20(12.7 \%)$ & $48(30.4 \%)$ & $16(10.1 \%)$ \\
\hline $\begin{array}{l}\text { 5. Having mental patients living within residential } \\
\text { neighbourhoods might be a good therapy, but the risks } \\
\text { to the residents are too great }\end{array}$ & $18(11.4 \%)$ & $39(24.7 \%)$ & $46(29.1 \%)$ & $42(26.6 \%)$ & $13(8.2 \%)$ \\
\hline $\begin{array}{l}\text { 6. Local residents have good reason to resist the } \\
\text { location of mental health services in their } \\
\text { neighbourhood }\end{array}$ & $37(23.4 \%)$ & $21.5 \%$ & $36(22.8 \%)$ & $24.7 \%$ & $12(7.6 \%)$ \\
\hline 7. Mental disorder is an illness like any other & $51(32.3 \%)$ & $53(33.5 \%)$ & $13(8.2 \%)$ & $24(15.2 \%)$ & $17(10.8 \%)$ \\
\hline $\begin{array}{l}\text { 8. We need to adopt a far more tolerant attitude towards } \\
\text { the mentally ill in our society }\end{array}$ & 61() $38.6 \%$ & $43(27.2 \%)$ & $17(10.8 \%)$ & $19(12 \%)$ & $18(11.4 \%)$ \\
\hline $\begin{array}{l}\text { 9. The mentally ill are far less of a danger than most } \\
\text { persons suppose }\end{array}$ & $36(22.8 \%)$ & $60(38 \%)$ & $21(13.3 \%)$ & $35(22.2 \%)$ & $6(3.8 \%)$ \\
\hline Subscale 2: Fear and avoidance & SA & A & $\mathbf{N}$ & $\mathbf{D}$ & SD \\
\hline 10. It is best to avoid anyone who has mental problems & $35(22.2 \%)$ & $39(24.7 \%)$ & $19(12 \%)$ & $29(18.4 \%)$ & $35(22.2 \%)$ \\
\hline $\begin{array}{l}\text { 11. I would not want to live next door to someone who } \\
\text { has been mentally ill }\end{array}$ & $31(19.6 \%)$ & $36(22.8 \%)$ & $27(17.1 \%)$ & $43(27.2 \%)$ & $21(13.3 \%)$ \\
\hline $\begin{array}{l}\text { 12. It is frightening to think of persons with mental } \\
\text { problems living in residential neighbourhoods }\end{array}$ & $16(10.1 \%)$ & $53(33.5 \%)$ & $15(9.5 \%)$ & $46(29.1 \%)$ & $28(17.7 \%)$ \\
\hline $\begin{array}{l}\text { 13. The best way to handle the mentally ill is to keep } \\
\text { them behind locked doors }\end{array}$ & $43(27.2 \%)$ & $35(22.2 \%)$ & $16(10.1 \%)$ & $32(20.3 \%)$ & $32(20.3 \%)$ \\
\hline $\begin{array}{l}\text { 14. Residents have nothing to fear from persons } \\
\text { coming into their neighbourhood to obtain mental health } \\
\text { services }\end{array}$ & $37(23.4 \%)$ & $51(32.3 \%)$ & $25(15.8 \%)$ & $32(20.3 \%)$ & $13(8.2 \%)$ \\
\hline $\begin{array}{l}\text { 15. Less emphasis should be placed on protecting the } \\
\text { public from the mentally ill }\end{array}$ & $31(19.6 \%)$ & $47(29.7 \%)$ & $32(20.3 \%)$ & $33(20.9 \%)$ & $15(9.5 \%)$ \\
\hline Subscale 3: Community mental health ideology & SA & A & $\mathbf{N}$ & $\mathbf{D}$ & SD \\
\hline $\begin{array}{l}\text { 16. The best therapy for many mental patients is to be } \\
\text { part of a normal community }\end{array}$ & $43(27.2 \%)$ & $58(36.7 \%)$ & $18(11.4 \%)$ & $24(15.2 \%)$ & $15(9.5 \%)$ \\
\hline $\begin{array}{l}\text { 17. The mentally ill should not be treated as outcasts of } \\
\text { society }\end{array}$ & & & & & \\
\hline $\begin{array}{l}\text { 18. As far as possible, mental health services should be } \\
\text { provided through community based facilities }\end{array}$ & $52(32.9 \%)$ & $40(25.3 \%)$ & $22(13.9 \%)$ & $26(16.5 \%)$ & $18(11.4 \%)$ \\
\hline $\begin{array}{l}\text { 19. No one has the right to exclude the mentally ill from } \\
\text { their neighbourhood }\end{array}$ & $62(39.2 \%)$ & $39(24.7 \%)$ & $17(10.8 \%)$ & $17(10.8 \%)$ & $23(14.6 \%)$ \\
\hline $\begin{array}{l}\text { 20. The mentally ill should be isolated from the rest of } \\
\text { the community }\end{array}$ & $65(41.1 \%)$ & $44(27.8 \%)$ & $16(10.1 \%)$ & $12(7.6 \%)$ & $21(13.3 \%)$ \\
\hline
\end{tabular}

As displayed in table below (Table 3), measures of central tendency and distribution shown that participants reflected less negative stereotypes in community mental health ideology subscale $\left(\mathrm{Md}=12 \%\right.$; Mo $=5 \%$; $25^{\text {th }}$ percentile $=8 \%$ : $75^{\text {th }}$ percentile $=16 \%)$ than Fear and avoidance $\left(\mathrm{Md}=16.5 \%\right.$; $\mathrm{Mo}=12 \% ; 25^{\text {th }}$ percentile $=13 \%: 75^{\text {th }}$ percentile $\left.=21.25 \%\right)$ and Open ended and pro integration ( $\mathrm{Md}=23 \%$; $\mathrm{Mo}=21 \% ; 25^{\text {th }}$ percentile $=13 \%$ : $75^{\text {th }}$ percentile $=21.25 \%$ ) subscales. Also the table indicating that participants reflected negative stereotypes on the total scores from the CAMI-S as confirmed by the measures of central tendency $\left(\mathrm{Md}=50 \%\right.$; $\mathrm{Mo}=69 \% ; 25^{\text {th }}$ percentile $=41.75 \%$ : $75^{\text {th }}$ percentile $=67 \%$ ). In addition, the extent of negatives stereotypes shows the evidence of contradictions between the subscales from the CAMI-S. 
Table 3: Results from CAMI-S subscale

\begin{tabular}{|c|c|c|c|c|c|}
\hline & & $\begin{array}{l}\text { Open minded and } \\
\text { pro integration }\end{array}$ & $\begin{array}{c}\text { Fear and } \\
\text { avoidance }\end{array}$ & $\begin{array}{c}\text { Community mental health } \\
\text { ideology }\end{array}$ & Total score \\
\hline \multirow{2}{*}{$\mathrm{N}$} & Valid & 158 & 158 & 158 & 158 \\
\hline & Missing & 0 & 0 & 0 & 0 \\
\hline \multicolumn{2}{|l|}{ Median } & 23.00 & 16.50 & 12.00 & 50.00 \\
\hline \multicolumn{2}{|l|}{ Mode } & 21 & 12 & 5 & 69 \\
\hline \multicolumn{2}{|c|}{ Std. Deviation } & 7.499 & 4.834 & 5.187 & 15.047 \\
\hline \multicolumn{2}{|l|}{ Skewness } & .126 & .042 & .356 & .192 \\
\hline \multicolumn{2}{|c|}{ Std. Error of Skewness } & .193 & .193 & .193 & .193 \\
\hline \multicolumn{2}{|l|}{ Minimum } & 9 & 7 & 5 & 25 \\
\hline \multicolumn{2}{|l|}{ Maximum } & 41 & 27 & 25 & 86 \\
\hline & 25 & 18.00 & 13.00 & 8.00 & 41.75 \\
\hline \multirow[t]{2}{*}{ Percentiles } & 50 & 23.00 & 16.50 & 12.00 & 50.00 \\
\hline & 75 & 31.00 & 21.25 & 16.00 & 67.00 \\
\hline
\end{tabular}

Association between demographic variables and CAMI-S (Subscales \& total score)

As stated in the research methods section, non-parametric tests were used for associations, these being the MannWhitney $\mathrm{U}$ test and the Kruskal-Wallis $\mathrm{H}$ test (Pallant, 2013). Apart from familiarity (level of contact), demographic variables (gender, background of students in secondary school, level of academic year) were seen as independent variables and scale scores on the CAMI-S as dependent variables. Finally, as stated in the methodology section, associations were seen as significant when they were less than $0.05(P=<0.5)$ (Pallant, 2013).

The Mann-Whitney U Test was used to compare specific participant's attitudes towards persons with a mental disorder (scores from the CAMI-S) with gender. Results of Mann-Whitney U Test suggested no significant associations between gender and student nurses stigmatizing attitude towards persons with a mental disorder on the CAMI-S (subscales or total scores). However, significant associations were revealed between background of student nurses and open minded and pro- integration $(z=-1.964 ; p=$ $.050, \mathrm{u}=901.5)$ and total score on the CAMI-S $(z=-2.212$; $\mathrm{p}=.07, \mathrm{u}=836)$.

Students with scientific background in secondary school recorded higher percentiles $\left(\mathrm{Md}=24 ; 25^{\text {th }}\right.$ percentile $=18$; $75^{\text {th }}$ percentiles $=31$ ) than students with social sciences background in secondary school who recorded lower $(\mathrm{Md}=$ 19; $25^{\text {th }}$ percentile $=16 ; 75^{\text {th }}$ percentiles $=27$ ) indicating that students with social sciences background have a greater extent of negative stereotypes than students with scientific background regarding open ended and pro integration subscale. This is similar to total score on the CAMI-S evidenced by the fact that students with scientific background recorded higher media $\left(\mathrm{Md}=51 ; 25^{\text {th }}\right.$ percentile= $42 ; 75^{\text {th }}$ percentiles $=68$ ) than students with social sciences background who recorded lower $\left(\mathrm{Md}=43 ; 25^{\text {th }}\right.$ percentile= $37 ; 75^{\text {th }}$ percentiles $=54$ ).

As illustrated in Table 4 below the Kryskal Wallis $\mathrm{H}$ Test revealed statistically significant associations between level of academic year with all of the sub scales scores "Open ended and pro integration $\left(x^{2} x^{2}(3,=158)=12.132, \mathrm{p}=.007\right)$, fear and avoidance $\left(x^{2} x^{2}(3,=158)=17.834, \mathrm{p}=.000\right)$ and community mental health ideology $\left(x^{2} x^{2}(3,=158)=39.778\right.$, $\mathrm{p}=.000)$, and the total CAMI-S score $\left(x^{2} x^{2}(3,=158)=25.338\right.$, $\mathrm{p}=.000$ ). The highest academic year group recorded a higher median score $(\mathrm{Md}=37)$ than other three remaining groups. These results suggest that students in year 4 are likely to reflect less negative stereotypes than students in students in year 1, 2 and 3.

Table 4. Association and Correlations

\begin{tabular}{|c|c|c|c|}
\hline CAMI-S Sub \& & Associations & & Correlations \\
\hline & $\begin{array}{l}\text { Background } \\
\text { of students in } \\
\text { secondary school }\end{array}$ & Academic year & $\begin{array}{l}\text { Level of contact/ } \\
\text { familiarity }\end{array}$ \\
\hline $\begin{array}{l}\text { Open minded and } \\
\text { pro integration }\end{array}$ & $\begin{array}{l}(z=-1.964 ; p=.050, \\
u=1150)\end{array}$ & $\left(x^{2} x^{2}(3,=158)\right.$ & \\
\hline Fear and avoidance & & $\begin{array}{l}\left(x^{2} x^{2}(3,=158)\right. \\
=17.834, \mathrm{p}=.000)\end{array}$ & $\begin{array}{l}\text { (rho- .268, } \\
n=158, p<0.001 \text { ) }\end{array}$ \\
\hline $\begin{array}{l}\text { Community mental } \\
\text { health ideology }\end{array}$ & & $\left(x^{2} x^{2}(3,=158)\right.$ & $\begin{array}{l}\text { (rho- } .209 \\
n=158, p<0.001 \text { ) }\end{array}$ \\
\hline Total score & $\begin{array}{l}(\mathrm{z}=-2.212 ; \mathrm{p}=.027, \\
\mathrm{u}=836)\end{array}$ & $\begin{array}{l}=39.1 / 8, p=.000) \\
\left(x^{2} x^{2}(3,=158)\right. \\
=25.338, \mathrm{p}=.000)\end{array}$ & $\begin{array}{l}\text { (rho- } .249 \\
n=158, p<0.001 \text { ) }\end{array}$ \\
\hline
\end{tabular}

Correlations between level of contact/ familiarity and CAMI-S (Subscales \& total score)

As displayed in table 4, scores achieved on the LOC, level of familiarity, were correlated with scores (sub scores and total score) achieved in the CAMI-S, the extent of stigmatizing attitudes, to identify possible strength and direction of this mediating relationship.

Results with significant correlations (strong, medium and small) are reported ( $p \square 0.5)$, Cohen's guide lines were used to determine the strength of the correlation; small $(\mathrm{rho}=.10$ to .29), medium (rho $=.30$ to .49) and strong (rho $=.50$ to 1.0) (Cohen, 1988), cited in Pallant (2013).

Correlations between participants' single highest score on the LOC, indicating their most intimate level of contact with a person with a mental disorder, and participants' scores 
on the CAMI-S subscales, and their total score achieved on the CAMI-S are presented in Table 3 below and described.

Spearman's rho correlation coefficient revealed no evidence of significant correlation between the open ended and integration subscale and LOC. However, the evidence of significant moderate negative correlation were found firstly, between LOC and the community and mental health ideology subscale(rho -.268, $n=158, p<0.001$ ); secondarily, between LOC and fear \& avoidance (rho- .209, n=158, $\mathrm{p}<0.001$ ) and lastly between LOC and total score (rho- .249 , $\mathrm{n}=158, \mathrm{p}<0.001)$. These results suggest that an increase in level of contact correlates with a decrease in scores in subscales and total scare respectively.

\section{Discussion}

The study revealed negative stereotypes amongst student nurses towards persons with mental disorders. Although participants seemed to agree, in principle, that mental health care facilities can, and should be, placed in communities, they also expressed a desire for social distance from persons with mental disorders. These findings are in line with international studies (Bjorkman et al., 2008; Arvaniti et al., 2009; Kopera, Suszek, Bonar, Myszka, Gmaj, Wojnar, 2015) and local studies conducted in Africa (Ukpong \& Abasiubong, 2010; Barke et al., 2011 and James, Omoaregba \& Okogbenin, 2012).

These contradictions and neutral positions might be the result of social desirability bias (Kopera, Suszek, Bonar, Myszka, Gmaj, Wojnar, 2015). This could reflect participants' recognition of the United Nations declaration of human rights, which asserts that everyone is equal and must be protected from any kind of discrimination, either direct or indirect, based on race, gender, sex, pregnancy, marital status, ethnic or social origin, colour, sexual orientation, age, disability, religion, conscience, belief, culture and language (United Nations, 1995; Republic of Rwanda, 2003). This declaration has been integrated into the constitutions of some African countries, including Rwanda, suggesting that no one can be discriminated against on the basis of his/her mental health status (Republic of Rwanda, 2003).

Also, the current study revealed association between demographic variables (background of student nurses in secondary and level of academic year) and subscales and the total scores from the CAMI-S. In addition, Familiarity did have a mediating effect on negative stereotypes and may be the foundation for changing attitudes within general health care settings.

However, limitations are to be highlighted such as the fact that the current study was conducted in only one School of Nursing \& Midwifery in Rwanda thus the results cannot be generalised to other Nursing Schools. The Hawthorne effect may have influenced results, whereby participants' responses might have been distorted due to the presence of the researcher in the research setting, specifically as the researcher is an employee of the research setting (Maree, 2008). In addition, due to the employee status of the researcher, management of the General Nursing department was very visible in their support of the data collection process. The researcher had anticipated potential discomfort and had therefore used implied consent, the posting of completed questionnaires and active reiteration of voluntary participation as strategies to reduce social desirability.

Additional research is recommended. Firstly, additional research is required to clarify the contradictions. It is suggested that scales that measure social desirability bias be included in further research studies to determine the extent of mediation or moderation of this construct. Secondly, intervention studies, specifically with student nurses, are required to obtain empirical data related to the combined effectiveness of disconfirming information and contact with people with mental disorders.

In response to the current evidence, in Nursing and Midwifery schools in Rwanda, it is suggested that curricula provide opportunities for exposure of students to persons with mental disorder within the whole process of training by increasing their collaboration with the specialist Psychiatric Hospital or Mental health service within the District Hospitals in Rwanda, thus increasing their level of contact; using simulated psychiatric patients in the skillslab before going into clinical practice should be mandatory.

Knowledge about mental illness can be enhanced through role playing, watching videos and group discussions. Workshops, seminars, conferences and discussions can be organized within the school which could include Mental Health Care users (MHCUs) to provide testimonies, which will in turn increase the level of contact amongst students and their lecturers.

In addition it is suggested that the curriculum review committee should review the curriculum of undergraduate nursing education and develop continuous mental health nursing modules and other related modules (Fundamentals of Behavioral Sciences) within the education programme that specifically address the issue of stigma.

\section{Acknowledgements}

School of Nursing \& Midwifery which accepted this study to be conducted on Nurses students undertaking their studies within the Department of General Nursing.

\section{Conflicts of interests}

There is no conflict of interests as longer as the study has not been funded by any institution and it has been conducted by only one researcher.

\section{Author contributions}

The researcher contributed in all phases of the research process; such as conceptual, design, empirical, analysis and dissemination phases. 


\section{References}

American Psychiatric Association. (2013). Diagnistic and Statistacal Manuel of MentalDisorder (5th ed.). Washington DC: American Psychiatric Publishing.

Arvaniti, A, Samakouri, M, Kalamara, E, Bochtsou, V, Bikos, C, \& Livaditis, M. (2009). Health service staff's attitudes towards patients with mental illness. Soc Psychiatry Psychiatr Epidemiol, 44, 658-665.

Barke, A, Nyarko, S, \& Klecha, D. (2011). The stigma of mental illness in Southern Ghana: attitudes of the urban population and patients views.Soc Psychiatry Psychiatr Epidemiol, 46, 1191-1202.

Bjorkman, T, Angelman, T, \& Jonsson, M. (2008). Attitudes towards people with mental illness: a crosssectional study among nursing staff in psychiatric and somatic care. Scand J Caring Sci, 22, 170177.

Burns, J K. (2011). The mental Health GAP in South Africa.A Human Rights Issue, 6,99-112.

Burns, N, \& Grove, S K. (2009). The Practice of Nursing Research : Appraisal, synthesis and generation of evidence (6th ed.). St. Louis, USA: Saunders.

Callaghan, P, Playle, J, \& Cooper, L. (2009). Mental Health Nursing skills. New York.

Corrigan, P W, Edwards, A B, Qreen, A, Diwan, S L, \& Venn, D. (2001). Prejudice, Social Distance, and Familiarity with Mental IIIness. Schizophrenia Bulletin, 27(2), 219-225.

Corrigan P.W, Powell K.J, Fokuo JK, Kosyluk K. (2014) Does Humor influence the stigma of mental illnesses? Journal of Nervous \& Mental Disease. 202 (5) 397-401.

Corrigan WP, Mittal D, Reaves CM, Haynes TF, Han X, Marris S. (2014) Mental health stigma and primary health care decision. Psychiatry Research. 218(12) $35-38$

Hogberg, T, Magnusson, A, Ewertzon, M, \& Lutzen, K. (2008). Attitudes towards mental illness in Sweden: Adaptation and development of the community attitudes towards mental illness questionnaire. Int $\mathrm{J}$ Ment Health Nurs, 17, 302-310.

Holmes, P, Corrigan, P, Williams, P, Canar, J, \& Kubiak, M A. (1999). Changing Attitudes about Schozophrenia. Schizophrenia Bulletin, 25(3), 447.

James, B O, Omoaregba, J O, \& Okogbenin, E O. (2012). Stigmatising attitudes towards persons with mental illness: a survey of medical students and interns from Southern Nigeria. Mental illness, 4(8), 32-34.

Kapungwe, A, Cooper, S, Mayeya, J, Mwanza, J, Mwape, L, Sikwese, A, Poverty Project Research Programme Consortium. (2010). Attitudes of primary health care providers towards people with mental illness: evidence from two districts in Zambia. International journal of Mental Health System, 4(21), 1-9

Kopera, M, Suszek, H,Bonar, E, Myszka, M, Gmaj, B, Ilgen, M, Wojnar, M. (2015). Evaluating explicit \& implicit Stigma of Mental Illness in Mental Health Professionals and Medical Students. Community Mental Health J, 51, 628-634.

Maree, K. (2008). First steps in Research (K. Maree Ed. 1st ed.). Pretoria: Van Schaik.

Morris, R, Scott, P N, Cocoman, A, Chambers, M, Guise, V, Valimaki, M, \& Clinton, G. (2011). Is the community attitudes towards the mentally ill scale valid for use in the investigation of Europian nurses'attitudes towards the mentally ill? A confirmatory factor analytic approach. Journal of Advanced Nursing, 68(2), 460-470.

Mwape, L, Mweemba, P, \& Kasonde, J. (2012). Strengthening the health systeme to enhance mental health in Zambia: A policy brief. International journal of technology assessment in heaklth care, 28(3), 294-300.

Mwape, L, Sikwese, A, Kapungwe, A, Mwanza, J, Flisher, A, Lund, C, \& Cooper, S. (2010). Integrating mental health into primary health care in Zambia: A care provider's perspective. International Journal of mental health system, 4(21), 1-9.

Pallant, I. (2013). SPSS survival manual ( $5^{\text {th }}$ ed.). Berkshire, England: Open University Publishers.

Polit, D F, \& Beck, C T. (2012). Nursing research: Generating and Assessing Evidence for Nursing Practice ( $9^{\text {th }}$ ed.). Philadelphia: Wolters Kluwer Health/ Lippincott Williams and Wilkins.

Republic of Rwanda. (2003). The constitution of the republic of Rwanda. Kigali.

Rwandan Ministry of Health. (2005). Health sector strategic plan 2009-2012. Kigali.

Rwandan Ministry of Health. (2009). Health sector strategic plan 2009-2012. Kigali.

Rwandan Ministry of Health. (2011). Mental Health Policy in Rwanda. Kigali.

Rwandan National Election Commission. (2011). The election law of local authorities. Kigali.

Ssebunnya, J, Kigozi, F, Kizza, D, Ndyanabangi, S, \& MHaPP Research Programme Consortium. (2010). Integration of Mental Health into Primary Health Care in a rural district in Uganda. Africa journal of Psychiatry, 12, 128-131.

Ukpong, D I, \& Abasiubong, F. (2010). Stigmatizing attitudes towards the mentally ill: A survey in Nigerian University Teaching Hospital. SAJP, 16(2), 56-60.

United Nations. (1995). Universal Declaration of Human Rights. Assessed on $28^{\text {th }}$ March 2013. Available at http://www.ohchr.org/en/udhr/pages/language. aspx? langid=eng.

University of Rwanda. (2013). Curriculum of Bachelor of Science with Honours. Kigali

Vedaste, B. \& Smith, A. A. H. (2016). 'In principle, Yes, In application, No': Rwandan nurses' support for integration of mental health services. African journal of nursing \& midwifery. 18(1), 170-182

Whiteford, H.A, Degenhardt, L., Rehm, J., Baxter, A.J., Ferrari, A,J, Erskine, H.E,Charson, F.J., Norman, R.E., Flaxman, A.D., Johns, N., Burstein, R.,

Murray,C.J. \& Vos, T. (2013). Global burden of deseases attribuable to mental and substance use diseorders: Findings from the global burden of deseases study 2010, Global health, 382 (9904), 1575-1586

World Health Organization. (2011). WHO Mental Health Atlas 2011. Assessed on $12^{\text {th }}$ July 2016. Available athttp://whqlibdoc.who.int/ publications/2011/9799241564359-engpdf.

World Health Organisation. (2013). Integrating mental health into primary care: A global perspective. Geneva. 